\title{
Assessment and rehabilitation of the Volos municipal theater according to the Greek Retrofitting Code
}

\author{
C. Maraveas ${ }^{1,2}$, K. Tasiouli ${ }^{1}$ \& K. Miamis ${ }^{1}$ \\ ${ }^{1}$ C. Maraveas Partnership, Consulting Engineers, Greece \\ ${ }^{2}$ School of Mechanical, Aerospace and Civil Engineering, \\ University of Manchester, UK
}

\begin{abstract}
The main objective of the present study is the assessment and retrofit of an existing reinforced concrete building. In particular, the study concerns the municipal theater of the city of Volos, Greece and it was carried out following the provisions and requirements of the Greek Retrofitting Code (KAN.EPE.), which adopts the Performance Based Design (PBD) concept. The theater was built during the 70s and was designed according to the Greek Royal Decrees of 1954 and 1959. The theater consists of the stage and the auditorium, which were analyzed independently, because they constitute two disjoint reinforced concrete (RC) structures. Their structural system consists of spatial frames and shear walls. The columns and the beams are simulated with beam elements with concentrated plasticity and the shear walls with equivalent diagonal truss elements which simulate the shear behavior of the wall structural element. Nonlinear static (Pushover) analysis is applied in order to estimate the seismic performance of the two structures for two performance objectives (A2 and B1 according to the provisions of KAN.EPE.). These correspond to the "Operational" and "Life Safety" performance levels for seismic hazard levels with a $50 \%$ and $10 \%$ probability of exceedance in 50 years, respectively. A retrofitting scenario is proposed for both the stage and the auditorium in order for the performance objectives to be met. It includes concrete jacketing of certain beams, columns and shear walls as well as strengthening of specific beams with fiber-reinforced polymers (FRPs).
\end{abstract}

Keywords: reinforced concrete structures, Pushover analysis, earthquake loading, seismic assessment, retrofit, rehabilitation, performance-based design. 


\section{Introduction}

Safety of existing structures under seismic actions can be assessed through analytical methods in conjunction with experimental data. It can be evaluated according to the principles of current seismic design codes. However, the uncertainties regarding the material properties and mechanical characteristics of the structural elements pose an issue for consideration. For this reason, studies in the field of performance-based design (PBD), seismic structural assessment and retrofit were conducted and a number of guidelines/codes were developed in the last decades. These include the US guidelines FEMA 356 [1], ASCE 41 [2], FEMA 273 [3], ATC-40 [4], part 3 of Eurocode 8 (EN1998-3) [5] and the Greek National Code for the Seismic Assessment and Rehabilitation of RC Buildings (KAN.EPE.) [6]. The common characteristic of these regulations is the adoption of static and dynamic nonlinear analysis, which are combined with appropriate performance objectives related to the inelastic deformations of the structural elements.

In the last years, nonlinear static (Pushover) analysis has been widely used for the seismic assessment of structures. Researchers $[7,8]$ have already emphasized the use of nonlinear analysis procedures in estimating the structural capacities of the existing and retrofitted structures subjected to various earthquake loads. Pushover analysis is generally applied to regular structures. A number of methods for the distribution of the lateral load along the height of the structure have been proposed in current codes. EN1998-3 [5] and KAN.EPE. [6] propose the "uniform" and the "modal" patterns for its distribution. In non-regular structures, torsional effects and the contribution of higher modes to the seismic response raise doubts regarding the application of this method. Despite the observation that, for such structures, pushover analysis results can differ from the actual response, KAN.EPE [6] permits the use of this method for their seismic assessment, provided that an additional elastic dynamic analysis is performed. Alternatively, EN1998-3 [5] and KAN.EPE. [6] suggest the use of inelastic dynamic analysis, in which the seismic action is introduced in the form of timedependent base acceleration (time-history analysis).

The majority of reinforced concrete (RC) structures in Greece were constructed before the application of the current seismic design codes. As a result, their design was based on either the obsolete principals/assumptions of the era or empirical practices. Such structures are extremely vulnerable to the effects of earthquake excitation. In this paper, the seismic assessment of the municipal theater of Volos, Greece (Figure 1) according to KAN.EPE. [6] is presented.

\section{Performance-based design and KAN.EPE. principles}

Performance-based seismic design has the following distinct features: (i) the structural engineer is allowed to select the performance level of the structure for a specific level of seismic hazard; (ii) the structure is assessed based on a series of performance objectives and, if necessary, retrofitting scenarios are proposed. 


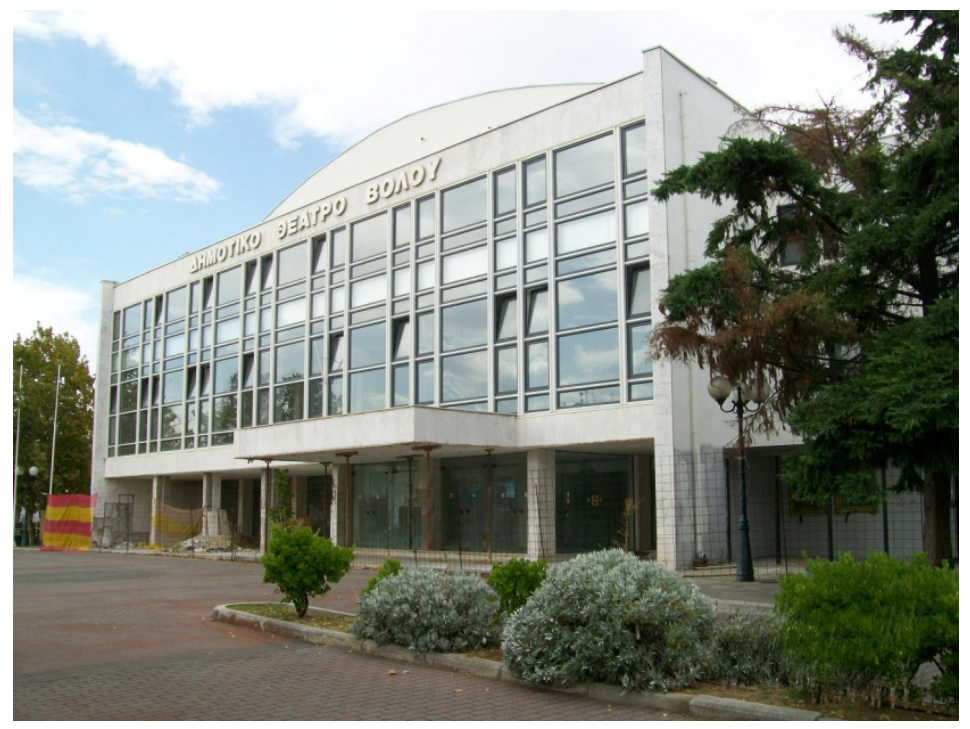

Figure 1: $\quad$ Picture of the municipal theater of Volos, Greece.

A crucial part in a performance-based seismic design procedure is the definition of the performance objectives, namely the target performance level for a specific hazard level. In KAN.EPE. [6], which adopts the PBD concept, the performance levels are defined as:

(i) Operational: the overall damage is characterized as very light and does not hinder the operation of the structure.

(ii) Life Safety: the overall damage level is characterized as repairable and does not endanger human lives.

(iii) Collapse prevention: the overall damage is characterized as severe, but the structure can still carry vertical loads.

The hazard levels related to seismic action are specified in KAN.EPE. [6] as:

(i) Occasional earthquake hazard level: the probability of exceedance in 50 years is $50 \%$, with a mean return period of 70 years.

(ii) Rare earthquake hazard level: the probability of exceedance in 50 years is $10 \%$, with a mean return period of 475 years.

The performance objectives defined in KAN.EPE. [6] for the assessment and retrofit of structures are presented in Table 1. 
Table 1: $\quad$ Performance objectives specified in KAN.EPE. [6].

\begin{tabular}{|c|c|c|c|}
\hline $\begin{array}{c}\text { Hazard level } \\
\text { (probability of } \\
\text { exceedance in 50 years) }\end{array}$ & $\begin{array}{c}\text { Operational } \\
\text { Performance } \\
\text { Level }\end{array}$ & $\begin{array}{c}\text { Life Safety } \\
\text { Performance } \\
\text { Level }\end{array}$ & $\begin{array}{c}\text { Collapse } \\
\text { prevention } \\
\text { Performance } \\
\text { Level }\end{array}$ \\
\hline $10 \%$ & $\mathrm{~A} 1$ & $\mathrm{~B} 1$ & $\Gamma 1$ \\
\hline $50 \%$ & $\mathrm{~A} 2$ & $\mathrm{~B} 2$ & $\Gamma 2$ \\
\hline
\end{tabular}

In a PDB procedure, all design criteria are tied to certain performance objectives. In KAN.EPE. [6], the structural performance of an existing building is assessed with reference to the performance objectives and a retrofit scenario is selected, so that the capacities of the structural elements exceed the demands resulting from seismic excitation. The capacity is expressed in terms of inelastic deformations, such as chord rotations and displacements, for "ductile" members and resistance for "brittle" structural elements. A classification of members with respect to ductility is given in KAN.EPE. [6].

\section{Nonlinear static analysis (pushover analysis)}

The purpose of the nonlinear static procedure (Pushover analysis) is to assess the structural performance globally and at element level, in terms of strength and deformation capacity. The model is "pushed" according to a predefined lateral load pattern. In order to determine the target displacement for various hazard levels, as required by the PDB framework, typically one of the following methods is adopted: the Capacity Spectrum method of ATC-40 [4], the Coefficient method of ASCE-41 [2] or the procedure given in EN1998-3 [5].

According to KAN.EPE. [6], the analysis is terminated when either the $150 \%$ of the target displacement is reached or the structure collapses. The target displacement, $d_{t}$, during a seismic event is measured at a characteristic node at the top of the structure. It is defined according to the mathematical expression [6] given in eqn (1):

$$
d_{t}=C_{0} C_{1} C_{2} C_{3}\left(T_{e}^{2} / 4 \pi^{2}\right) S_{e}(T)
$$

where $\mathrm{C}_{0}, \mathrm{C}_{1}, \mathrm{C}_{2}$ and $\mathrm{C}_{3}$ are modification factors, $\mathrm{T}_{\mathrm{e}}$ is the effective period of the building in the direction under consideration and $\mathrm{S}_{e}(\mathrm{~T})$ the elastic response spectrum acceleration, corresponding to $\mathrm{T}_{\mathrm{e}} \cdot \mathrm{C}_{0}$ relates the spectral displacement of an equivalent elastic system with stiffness $\mathrm{K}_{\mathrm{e}}$ (secant stiffness at $60 \%$ of the base shear) to the actual displacement at the top of the elastic-plastic structure. $\mathrm{C}_{1}$ is the ratio of the expected maximum inelastic displacement to the linear elastic one. $\mathrm{C}_{2}$ accounts for the effect of the hysteresis shape on the maximum displacement and $\mathrm{C}_{3}$ accounts for P- $\Delta$ effects. FEMA 440 [9] guidelines provide expressions for calculating the effective damping/period and for scaling the demand spectrum based on the hysteretic model of the system. These expressions were adopted in the analyses presented here. 


\section{Simulation parameters}

In this study, the seismic behavior of the municipal theater located in the city of Volos, Greece is assessed according to the regulations of KAN.EPE. [6]. The theater is a RC structure built around 1970. Afterwards, a retrofit scenario is proposed for both parts of the theater; the stage and the auditorium. Separate analyses were conducted for each one of them. The assessment is based on the performance objectives set by the owner (A2 and B1 according to Table 1).

Earthquake action was determined via the response spectrum given in EN1998-1 [10], which was obtained for the following parameters: i) soil type D ii) importance factor $\gamma_{\mathrm{I}}=1.20$ for the auditorium and $\gamma_{\mathrm{I}}=1.00$ for the stage iii) soil parameter $\mathrm{S}=1.35$, iv) characteristic periods: $\mathrm{T}_{\mathrm{B}}=0.20 \mathrm{sec}, \mathrm{T}_{\mathrm{C}}=0.80 \mathrm{sec}$, $\mathrm{T}_{\mathrm{D}}=2.5 \mathrm{sec}$ v) $5 \%$ damping and vi) peak ground acceleration $0.24 \mathrm{~g}$ (seismic hazard with a probability of exceedance $10 \%$ in 50 years) and $60 \% \times 0.24 \mathrm{~g}$ (seismic hazard with a probability of exceedance $50 \%$ in 50 years). A summary of the vertical loads used in the analysis of the structures is given in Table 2.

Table 2: $\quad$ Loads considered in the analyses of the structures.

\begin{tabular}{|l|c|}
\hline \multicolumn{2}{|c|}{ Permanent Loads } \\
\hline Concrete self-weight & $25.00 \mathrm{kN} / \mathrm{m}^{3}$ \\
\hline Structural steel self-weight & $78.50 \mathrm{kN} / \mathrm{m}^{3}$ \\
\hline Floor loads - generally/stage corridors & $3.00 / 1.50 \mathrm{kN} / \mathrm{m}^{2}$ \\
\hline Roof loads & $3.00 \mathrm{kN} / \mathrm{m}^{2}$ \\
\hline Outer/ Inner masonry partitions & $3.60 / 2.10 \mathrm{kN} / \mathrm{m}^{2}$ \\
\hline \multicolumn{2}{|c|}{ Live Loads } \\
\hline Floor loads/Roof loads & $5.00 / 2.00 \mathrm{kN} / \mathrm{m}^{2}$ \\
\hline
\end{tabular}

The material properties for the existing structures were determined via testing of samples taken from the field. The type and number of the conducted tests followed the regulations of KAN.EPE. [6]. Based on these, the concrete class was determined to be C12/15, while steel reinforcement was identified as S220. The materials used for the retrofitting of the structures were: cast in situ concrete C25/30, shotcrete Cs30, steel reinforcement B500c and fiber-reinforced polymers (FRPs). The material safety factors are defined in KAN.EPE. [6] and differ according to the phase of the study (assessment or retrofit). Simulation of the materials was based on the constitutive laws given in the Eurocodes $[5,11]$ and KAN.EPE. [6].

The existing structure was simulated as a 3D frame structure using the commercial software SAP2000 v15.2.1. [12], which uses the finite element method (FEM) and specializes in non-linear analysis of structures. The beams and columns of the structure were simulated as beam elements with concentrated plasticity. The shear walls were simulated via two equivalent diagonal truss elements in compression [6]. The inelastic behavior of the structural elements was defined through moment-rotation diagrams for the beams and columns and 
via axial force-deformation diagrams for the diagonal truss elements according to KAN.EPE. [6]. The latter are used for the simulation of the structural failure in compression, while the tensile failure is ignored.

The design checks tied with the fulfillment of the performance objectives are thoroughly defined in the regulations of KAN.EPE. [6]. For the "ductile" structural members, chord rotation limitations apply depending on the performance level considered. On the contrary, for the "brittle" elements, capacity is checked in terms of resistance. Especially for shear walls, axial deformations of the simulation truss elements are subjected to limits according to the performance level. Moreover, the cyclic shear resistance of all members should exceed the shear forces induced by seismic actions. All checks must be satisfied for the following combinations [6]:

$$
\begin{aligned}
& S_{d}=1.35 \sum_{j} G_{k j} ”+” 1.50 \sum_{i} Q_{k i} \\
& S_{d}=\sum_{j} G_{k j} ”+\cdots E_{d} \cdots+\cdots \sum_{i} \psi_{2 i} Q_{k i}
\end{aligned}
$$

where "+" implies "to be combined with", the summation symbol " $\Sigma$ " implies "the combined effect of", $\mathrm{G}_{\mathrm{kj}}$ denotes the characteristic value of the permanent action $\mathrm{j}, \mathrm{Q}_{\mathrm{ki}}$ refers to the characteristic value of the variable action $\mathrm{i}$ and $\psi_{2 \mathrm{i}}$ is the combination coefficient for the quasi-permanent action $i$, here selected equal to 0.30 for the stage and 0.60 for the auditorium [13].

Earthquake loading " $\mathrm{E}_{\mathrm{d}}$ " is defined according to the following load combinations for the "uniform" (eqn 4) and "modal" distributions of the horizontal load (eqn 5) along the height of the structure:

$$
\begin{gathered}
E_{d}= \pm E_{X} \pm 0.30 E_{Y} \text { or } E_{d}= \pm E_{Y} \pm 0.30 E_{X} \\
M_{d}= \pm M_{X} \pm 0.30 M_{Y} \text { or } M_{d}= \pm M_{Y} \pm 0.30 M_{X}
\end{gathered}
$$

where $E_{X}$ and $E_{Y}$ denote the seismic action for the "uniform" distribution along height in the $\mathrm{X}$ and $\mathrm{Y}$ directions, respectively, while $\mathrm{M}_{X}$ and $\mathrm{M}_{\mathrm{Y}}$ denote the seismic action for the "modal" distribution along height in the $\mathrm{X}$ and $\mathrm{Y}$ directions, respectively.

\section{Numerical analysis}

As mentioned in the previous paragraph, the theater consists of two parts, which were analyzed independently, as they constitute two disjoint RC structures. The study was conducted in two phases for each structure. In the first phase, their performance was assessed via pushover analysis as specified in the Greek Retrofitting Code (KAN.EPE.) [6]. The acceptance criteria were defined in terms of deformation for two different performance levels (Operational and Life safety). The deficiencies of each structure were located and a retrofit scenario was proposed. The second phase was the seismic assessment of the retrofitted structures according to the same code [6]. 


\subsection{Analysis of the existing building of the auditorium}

The auditorium is a RC structure with a total height of approximately $13.75 \mathrm{~m}$, five main levels (with elevations at: $+4.00 \mathrm{~m},+6.72 \mathrm{~m},+9.60 \mathrm{~m},+11.40 \mathrm{~m}$ and $+13.75 \mathrm{~m}$ ) and plan dimensions approximately $39.0 \mathrm{~m} \times 39.0 \mathrm{~m}$. Its structural system mainly consists of spatial RC frames and shear walls. Two corridors run along the longitudinal direction, while the main transverse frames are located near the entrance of the building (Figure 2). The maximum grid spacing (in plan) is $5 \mathrm{~m}$ and the average story height is $3 \mathrm{~m}$. The structure is supported by square columns with a cross-section of $30 / 30 \mathrm{~cm}$ and by circular columns with a diameter of $\mathrm{D}=35 \mathrm{~cm}$. The beams typically range from $\mathrm{b} / \mathrm{h}=20 / 40 \mathrm{~cm}$ to $\mathrm{b} / \mathrm{h}=30 / 60 \mathrm{~cm}$, where $\mathrm{b}$ is the width and $\mathrm{h}$ is the height of the cross-section. The shear walls have a thickness of $20 \mathrm{~cm}$, while slabs are typically $10-15 \mathrm{~cm}$ thick. The foundation of the building consists of spread footings (foundation level: $0.66 \mathrm{~m}$ ) connected with strap beams. The roof of the basement is located at level $+4.00 \mathrm{~m}$. It has to be mentioned that, even though five main levels can be noticed, the slabs at each level do not constitute rigid diaphragms, because of the existence of large openings. The roof of the auditorium is supported by a steel truss. A 3D view of the structural frame of the auditorium is depicted in Figure 3.

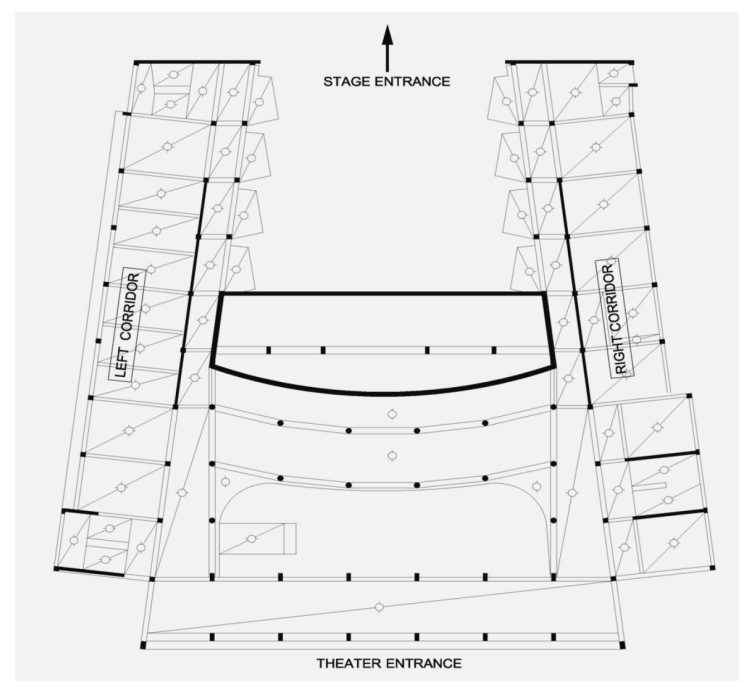

Figure 2: $\quad$ Plan of the auditorium of the theater. 


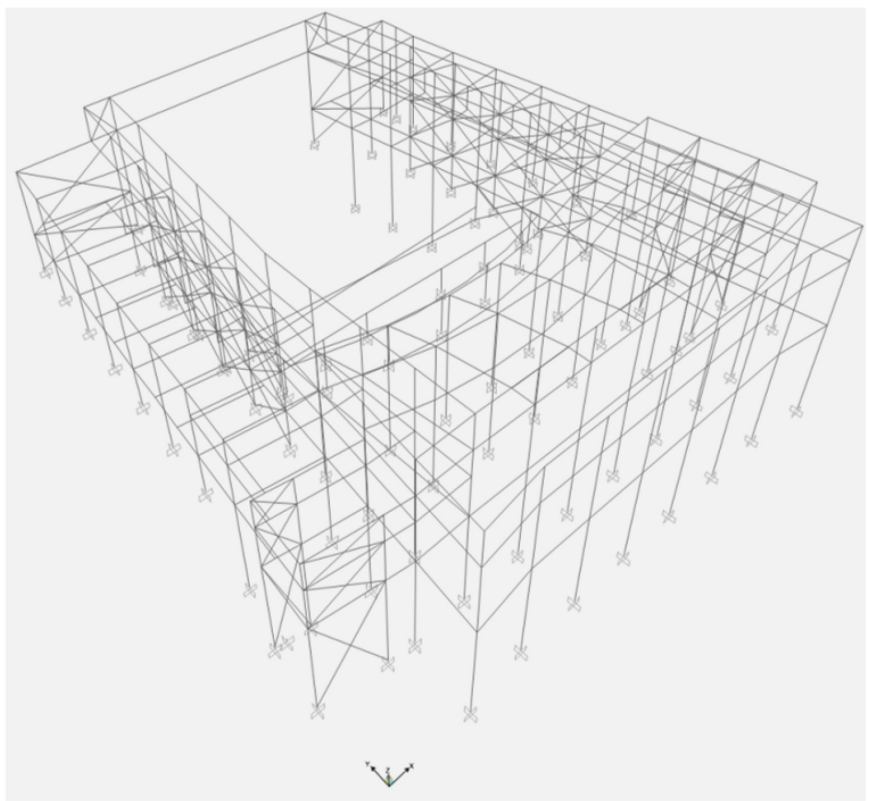

Figure 3: $3 \mathrm{D}$ view of the simulation model created to analyze the auditorium.

Figure $4 \mathrm{a}$ and Figure $4 \mathrm{~b}$ present the performance of the existing structure for the most critical load combination, obtained from eqns (3), (4), (5) and objectives A2 and B1, respectively. Performance is assessed in terms of rotation at the end section of the members. The state of the elements' rotation is presented in color according to the accompanying colored bar. The depicted rotation limits are explained as follows: B: yield, IO: Immediate Occupancy, LS: Life Safety, CP: Collapse Prevention, C: collapse, D: strength degradation, E: permanent deformation with substantially reduced strength.

More specifically, for the performance objective A2 (Figure 4a), the endsection rotation values are not allowed to exceed the state of immediate occupancy. Only states B (magenta color) and IO (blue color) are acceptable. Similarly, the life safety state (cyan color) cannot be exceeded for the B1 performance objective (Figure 4b). Therefore, according to the analysis results, the structure must be retrofitted for rotations to satisfy the limits set by the selected performance objectives. Moreover, the response of the structure in the longitudinal direction is governed by the existence of two very stiff shear walls, which attract a large portion (approximately 70\%) of the total seismic force. Besides their low rotational deformation capacity, the inadequate shear resistance of these walls severely affects the capability of the structure to resist lateral loads. In the transverse direction, exceedance of the rotation limits is mainly observed for the frames and shear walls in the region near the entrance of the auditorium. 


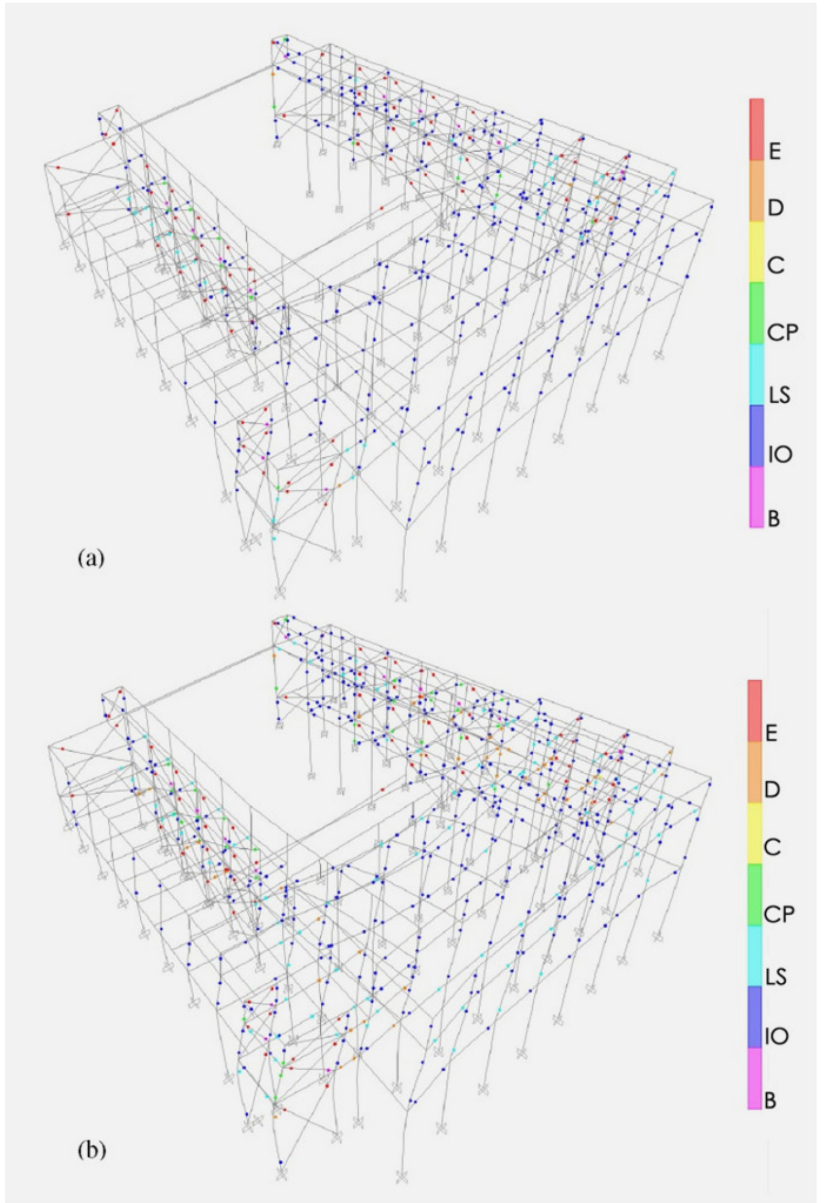

Figure 4: Deformed shape of the existing structure of the auditorium for the critical load combination $\left(\mathrm{M}_{\mathrm{X}}+0.3 \mathrm{M}_{\mathrm{Y}}\right)$ and (a) A2 or (b) B1 performance objectives.

\subsection{Analysis of the retrofitted building of the auditorium}

Based on the seismic assessment of the auditorium, a retrofitting scenario was proposed (Figure 5). In the longitudinal direction, the two main shear walls were retrofitted with cast in-situ concrete jacketing ( $20 \mathrm{~cm}$ thickness), in order for their resistance and deformation capacity to be increased. The two transverse main frames (near the entrance) were also retrofitted with in-situ concrete jacketing of $20 \mathrm{~cm}$ thickness. Moreover, shotcrete with an average thickness of $10 \mathrm{~cm}$ was applied as jacketing for all transverse shear walls. The cyclic shear resistance requirements set by KAN.EPE. [6] are not met for a number of beams at various levels of the structure. For this reason, these members where strengthened against shear failure with FRPs. 


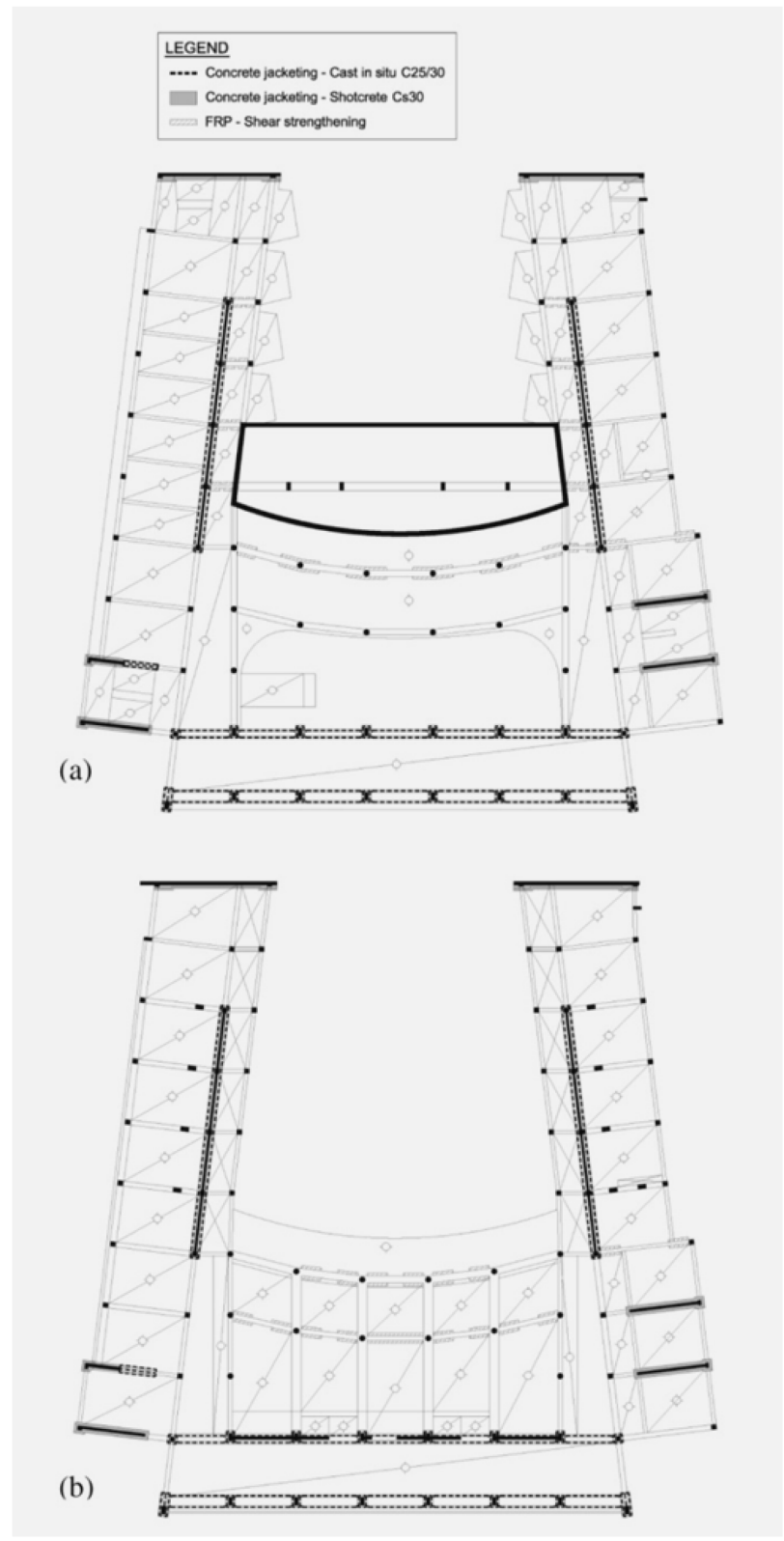

Figure 5: Retrofitting scenario for the auditorium (a) at elevation $+6.72 \mathrm{~m}$ and (b) at elevation $+11.40 \mathrm{~m}$.

The suggested interventions are expected to redistribute the major portion of the seismic forces to the retrofitted elements, increase the stiffness of the structure in both directions and improve the capacity of "weak" structural 
elements. The analysis results verify these statements. Figure 6 shows the performance (according to objectives A2 and B1) of the retrofitted structure for the most critical load combination. Once again, this is presented in terms rotations at end-sections of the elements. It can be observed that, after the implementation of the retrofitting scenario, these rotations do not exceed the limits set by A2 and B1 performance objectives. The red colored dots in the diagonals simulating the shear wall response correspond to exceedance of their tensile strength, which is assumed to be zero according to KAN.EPE. [6]. These red dots were neglected during the seismic assessment of the structure.

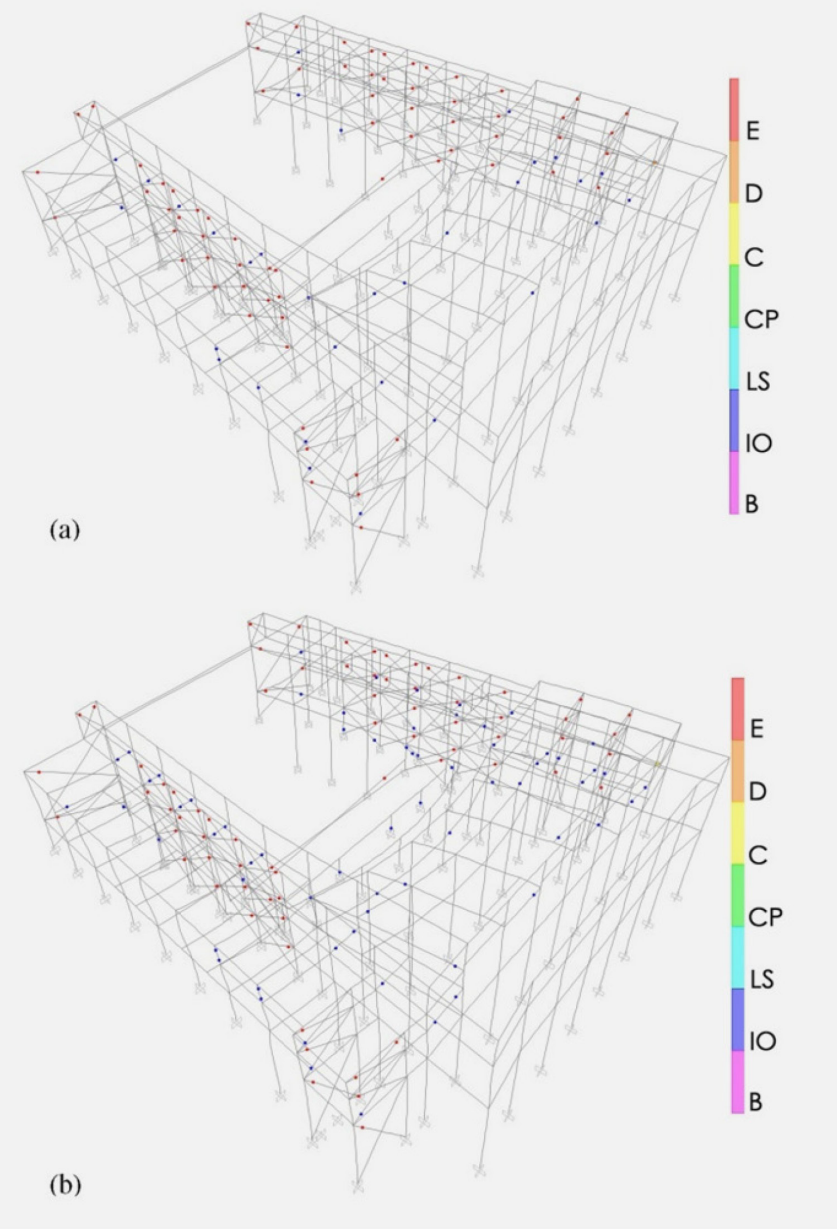

Figure 6: Deformed shape of the retrofitted structure of the auditorium for the critical load combination $\left(\mathrm{M}_{\mathrm{X}}+0.3 \mathrm{M}_{\mathrm{Y}}\right)$ and (a) $\mathrm{A} 2$ or (b) B1 performance objectives. 


\subsection{Analysis of the existing building of the stage}

The stage is a RC building $20.37 \mathrm{~m}$ high which consists of six levels $(+5.12 \mathrm{~m}$, $+11.10 \mathrm{~m},+13.35 \mathrm{~m},+15.62 \mathrm{~m},+17.87 \mathrm{~m}$ and $+20.37 \mathrm{~m})$. The structure has approximate plan dimensions $49.0 \mathrm{~m}$ x $25.0 \mathrm{~m}$ at the first level and $20.0 \mathrm{~m} \mathrm{x} 15.0 \mathrm{~m}$ at the remaining ones. Elevation $+5.12 \mathrm{~m}$ corresponds to the roof of the basement. The structural system of the stage is formed from four concrete cores with a thickness of $20 \mathrm{~cm}$. These are connected with beams spanning $10 \mathrm{~m}$ in the transverse and $15 \mathrm{~m}$ in the longitudinal direction. Their cross section is approximately $\mathrm{b} / \mathrm{h}=30 / 90 \mathrm{~cm}$. Additional spatial frames and shear walls exist below the elevation of $+13.35 \mathrm{~m}$. Column cross sections are typically $\mathrm{b} / \mathrm{h}=60 / 30 \mathrm{~cm}$ and $\mathrm{b} / \mathrm{h}=30 / 30 \mathrm{~cm}$. A steel truss supports the roof. The building is founded on spread footings (at an elevation of $-0.02 \mathrm{~m}$ ), which are connected with strap beams. In Figure 7, a 3D view of the structural framing of the stage is depicted.

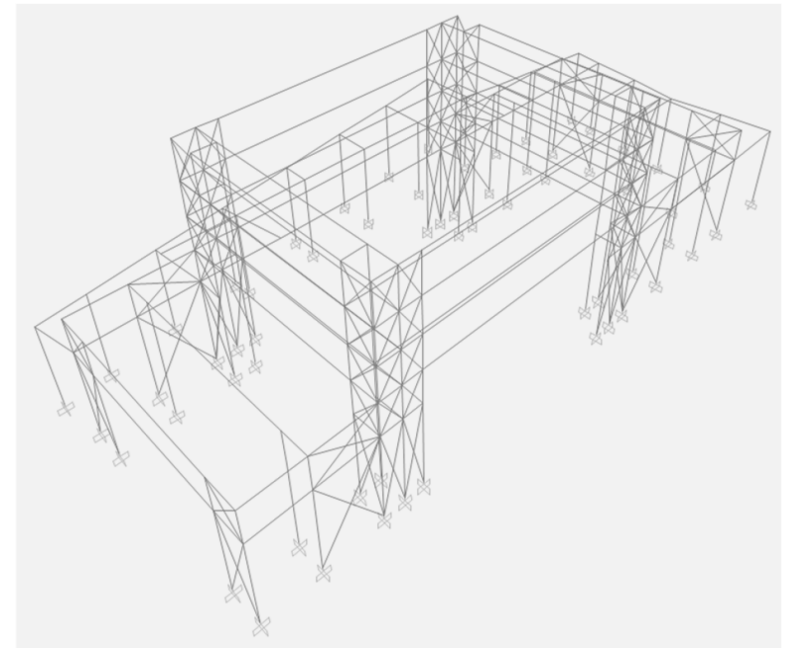

Figure 7: $3 \mathrm{D}$ view of the simulation model created to analyze the stage.

The seismic assessment of the stage is given in Figure 8a (objective A2) and Figure $8 \mathrm{~b}$ (objective $\mathrm{B} 1$ ). The rotation at the end of the elements is given in the accompanying color bar. Explanation of the relevant symbols has already been given in the previous section.

According to the linear static analysis results, the bending and shear resistance of certain beams located at level $+5.12 \mathrm{~m}$ is exceeded. This is also observed for beams with spans ranging from $10 \mathrm{~m}$ to $15 \mathrm{~m}$. Additionally, the pushover analysis showed that their rotational capacities do not satisfy the appropriate limits for either performance objective. Moreover, the seismic response of the structure is majorly affected by the behavior of the four concrete cores, whose capacity, in terms resistance and ductility, is exceeded under earthquake action. Based on these observations, a retrofitting scenario is proposed. 


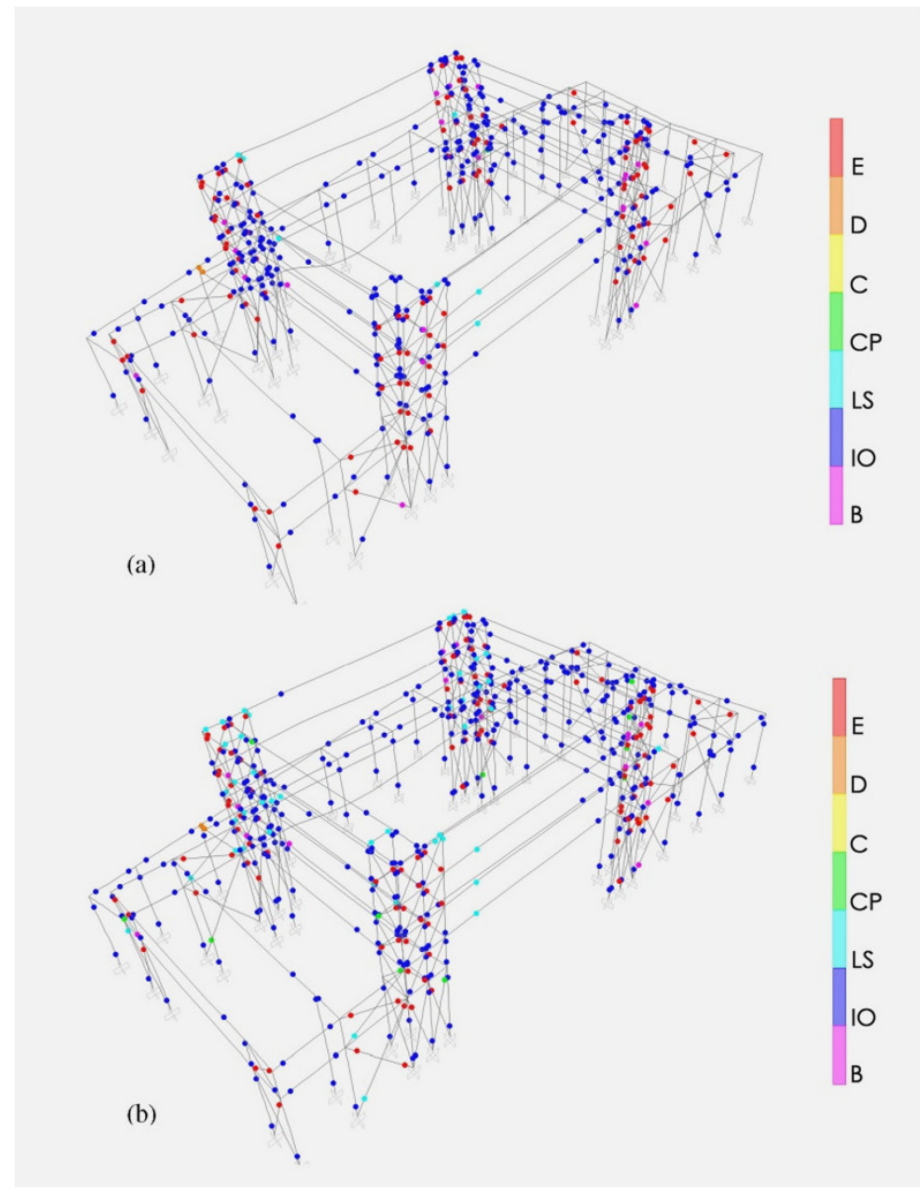

Figure 8: Deformed shape of the existing structure of the stage for the critical load combination $\left(\mathrm{M}_{\mathrm{X}}+0.3 \mathrm{M}_{\mathrm{Y}}\right)$ and (a) A2 or (b) B1 performance objectives.

\subsection{Analysis of the retrofitted building of the stage}

A presentation of the retrofitting scenario proposed for the stage is shown in Figure 9a (level $+5.12 \mathrm{~m})$ and Figure $9 \mathrm{~b}$ (level $+17.87 \mathrm{~m})$. This comprises of shotcrete jacketing of the four concrete cores and the beams connecting them, in order for their stiffness and resistance to be increased. As a consequence, the remaining load-bearing elements will attract less load due to stiffness redistribution in the structural system. For the beams (level $+5.12 \mathrm{~m}$ ) whose resistance under static loads is exceeded, strengthening against bending and shear failure with FRPs is proposed. 
(a)

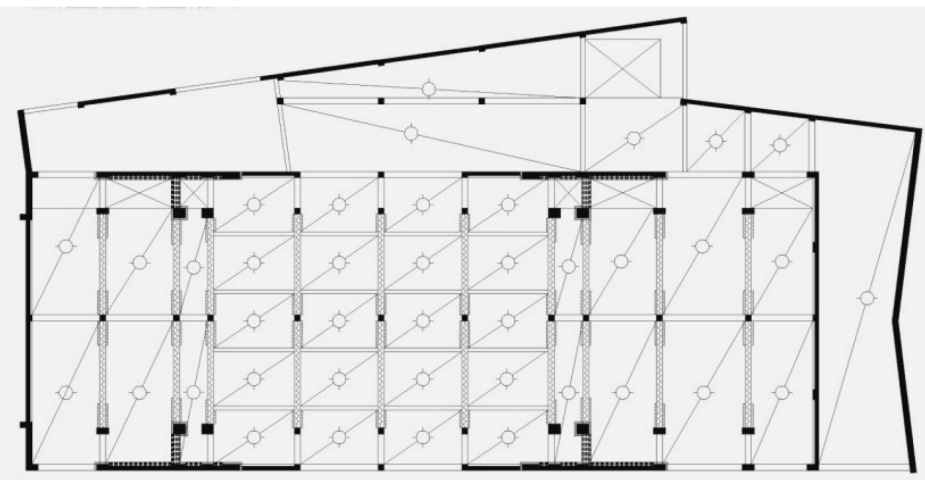

(b)
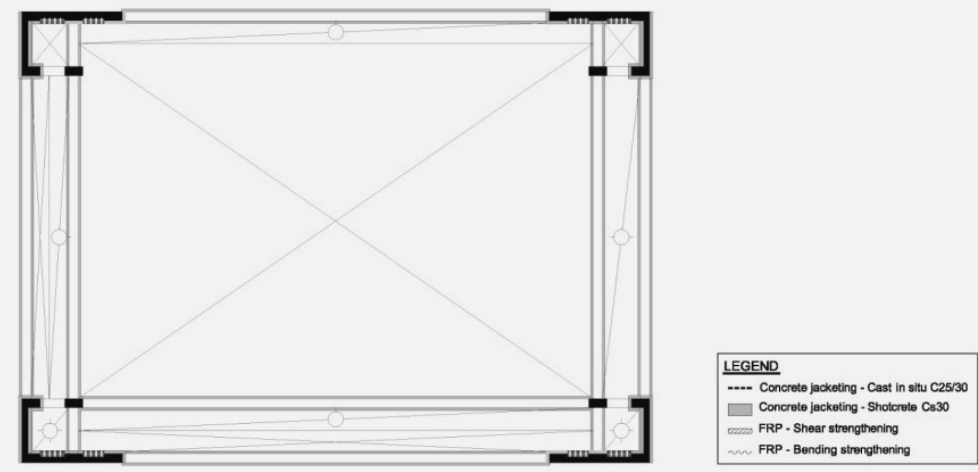

Figure 9: Retrofitting scenario for the stage (a) at elevation $+5.12 \mathrm{~m}$ and (b) at elevation $+17.87 \mathrm{~m}$.

In Figure 10a (objective A2) and Figure 10b (objective B1), the performance of the retrofitted stage is presented (in terms of rotational capacity). Results refer to the most critical load combination. Similarly to the auditorium, the suggested retrofitting scenario fulfills the requirements of KAN.EPE [6] for the required performance objectives, as end-member rotation does not exceed the relevant limits, with the exception of few beams at level $+11.10 \mathrm{~m}$. However, these are considered secondary elements and do not affect the global response of the structure to earthquake loading. Once again, the red colored dots in the shear diagonals were neglected during the seismic assessment of the structure, as they correspond to tensile strength exceedance (zero tensile strength was assigned to the diagonals as mandated by KAN.EPE. [6]. 


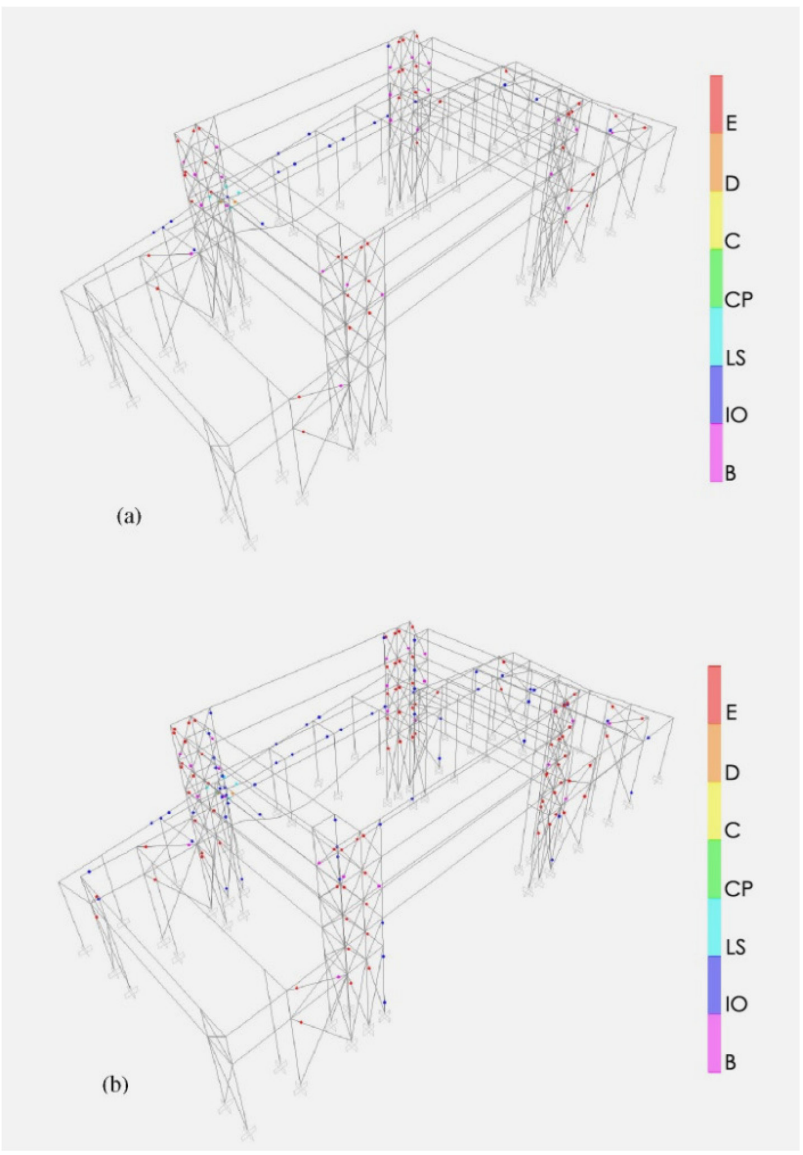

Figure 10: Deformed shape of the retrofitted structure of the stage for the critical load combination $\left(-\mathrm{E}_{\mathrm{X}}-0.3 \mathrm{E}_{\mathrm{Y}}\right)$ and (a) $\mathrm{A} 2$ or (b) B1 performance objectives.

\section{Conclusions}

This paper presented the seismic assessment of the municipal theater of the city of Volos, Greece according to the provisions of the Greek Retrofitting Code (KAN.EPE.). Nonlinear static (Pushover) analysis was applied to evaluate the seismic performance of the two parts of the theater (stage and auditorium). The two performance objectives considered were A2 ("Operational" performance level for a seismic hazard with probability of exceedance $50 \%$ in 50 years) and B1 ("Life Safety" performance level for a seismic hazard with probability of exceedance $10 \%$ in 50 years). The analyses results showed that neither structure fulfils the performance objectives set by the owner. For this reason, a retrofit scenario was proposed for each building. For the auditorium, jacketing with insitu concrete and shotcrete was proposed for the structural elements crucial to its 
seismic response (shear walls in the longitudinal direction and main transverse frames/shear walls). Strengthening of the four cores and the beams connecting them via shotcrete jacketing was suggested for the retrofitting of the stage. A number of beams were also strengthened in flexure and shear under vertical loads by attachment of FRP materials. Analysis showed that the retrofit proposal was effective in covering the requirements of the Greek Retrofitting Code (KAN.EPE.). Moreover, it provided a cost-effective solution and viable solution for the enhancement of the seismic performance of the theater.

\section{References}

[1] Federal Emergency Management Agency (FEMA). FEMA 356, Prestandard and Commentary for the Seismic Rehabilitation of Buildings, Washington, D.C, 2000.

[2] American Society of Civil Engineers (ASCE). ASCE/SEI Standard 41-06, Seismic Rehabilitation of Existing Buildings, Reston, VA, US, 2006.

[3] Federal Emergency Management Agency (FEMA). FEMA 273, NEHRP Guidelines for the Seismic Rehabilitation of Buildings, Washington, D.C, 1997.

[4] Applied Technology Council (ATC). ATC-40, Seismic evaluation and retrofit of concrete buildings, Redwood City, California, US, 1996.

[5] European Committee for Standardization. Eurocode 8: Design of structures for earthquake resistance - Part 3: Assessment and retrofitting of buildings, European Standard EN 1998-3. Brussels, Belgium, 2005.

[6] Earthquake Planning and Protection Organization (EPPO). Greek Retrofitting code (KAN.EPE.), Athens, Greece, 2011.

[7] Mitropoulou C.C., Lagaros N.D., Papadrakakis M., Life-cycle cost assessment of optimally designed reinforced concrete buildings under seismic actions, Reliability Engineering and System Safety; Vol. 96, pp. 1311-1331, 2011.

[8] Lagaros N.D., Mitropoulou, C.C., The effect of uncertainties in seismic loss estimation of steel and reinforced concrete composite buildings, Structure and Infrastructure Engineering, 9(6): 546-566, 2013.

[9] Federal Emergency Management Agency (FEMA). FEMA 440, Improvement of Nonlinear Static Seismic Analysis Procedures, Washington, D.C, 2005.

[10] European Committee for Standardization. Eurocode 8: Design of structures for earthquake resistance - Part 1: General rules, seismic actions and rules for buildings, European Standard EN 1998-1, Brussels, Belgium, 2005.

[11] European Committee for Standardization. Eurocode 2: Design of concrete structures - Part 1-1: General rules and rules for buildings, European Standard EN 1998-3. Brussels, Belgium, 2005.

[12] Computer \& Structures, Inc., SAP2000 v15, Integrated Software for Structural Analysis and Design, Berkley, CA, US.

[13] European Committee for Standardization. Eurocode: Basis of Structural Design, European Standard EN 1990, Brussels, Belgium, 2002. 